What we need is a flexible system that

allows the dentist to choose a recall

interval based on a professional opinion

of the best timescale .....

\title{
Six-monthly check-ups
}

Rumour has it that part of the origin of the six-monthly dental check-up as a routine came from a television programme called Amos and Andy in the middle of the last century, and once the idea had been suggested on the show the American Dental Association thought this was such an excellent opportunity for dentists they adopted it in the USA, and the rest (as they say) is history. Whether this story has even the slightest hint of truth or not - it remains a good story, especially now that the issue of the frequency of regular dental attendance is in the news.

It would seem that the Government, in its current mood of evidence-based healthcare, has questioned the need for a regular recall interval of six months for everyone. This is hardly surprising, especially since the time interval of six months has been questioned in the past and is often thought to be too rigid. The National Institute for Clinical Excellence (NICE) is currently investigating the whole issue and will report soon. No doubt one of the papers it will consult is the paper in this issue of the $B D J$ by Davenport et al, a systematic review of the evidence base. Alas, NICE will find little comfort for its deliberations in this paper, as the paper reports that there is no existing high quality evidence to support the practice of six-monthly dental check-ups, nor any evidence to refute it. In other words, we simply do not know.

But suppose we take the official organisations and the researchers out of the picture for a moment and look at what actually happens in dental practice? As long as I can remember general practitioners have tended to adopt a fairly relaxed approach to the interval between dental examinations, tending to adapt the interval to a variety of factors that they judged (in a very anecdotal manner) to be appropriate.

Often the patient's wishes are the most important factor. Some patients appear to need the security of regular visits every six months or so, and genuinely become distressed at the thought of extending the time period. Even when advised by their dentist that they could extend the interval by several months they decline, as if believing that the movement of a mirror inside their mouth accompanied by some form of charting jargon to the dental nurse will insure them against dental problems in the future. I suspect even they (the patients) know that unexpected events can occur between check-ups, but they like the idea that a regular examination every six months is more likely to identify future problems early (even if there is no evidence base for this belief).

Next in the list is the perceived clinical need. Some patients seem to be able to exist very happily with a recall interval of one or two years while others require recalls every two or three months. Identifying the right time period is a totally intuitive process that dentists operate and lacks any form of evidence, so we do not know if it works effectively or not. However, as the paper in this $B D J$ reminds us, we also do not know if anything else works effectively either.

Other factors that influence the choice of recall time interval include how busy the dentist (or patient) is, what recall method the practice uses (if any) and in the case of government-funded dental healthcare systems, the requirements of the system. If the regulations state dentists can only claim a fee for a dental check-up every six months then that will obviously affect their behaviour.

Finally, I cannot leave the subject without mentioning that there is always an unfortunate agenda running throughout this subject - the suspicion that dentists are seeing patients more often than they need to, a message the media is only too happy to report as often as it can. What is rarely mentioned is the reverse of this, how some patients may suffer because there is currently no NHS provision for a dental check-up more often than six-monthly when appropriate. What we need in the future NHS system for primary care is a flexible system that allows the dentist to choose a recall interval based on a professional opinion of the best timescale, whether it be two months or 18 months. Perhaps it will still happen.

$$
\begin{array}{r}
\text { Mike Grace, Editor } \\
\text { m.grace@bda-dentistry.org.uk } \\
\text { doi:10.1038/sj.bdj.4810329 }
\end{array}
$$

